Sri Lanka J. Aquat. Sci. 16 (2011) 27-39

\title{
Analysis of Bile Fluorescence Profiles of Feral Nile tilapia as Biomarkers of Exposure to Polycyclic Aromatic Hydrocarbons: Associations with the Rainfall
}

\author{
Chamini K. Hemachandra and Asoka Pathiratne* \\ Department of Zoology, Faculty of Science, University of Kelaniya, \\ Kelaniya, Sri Lanka. \\ *Corresponding author (asoka@kln.ac.lk)
}

\begin{abstract}
The present study was conducted to evaluate the potential use of bile fluorescence patterns of feral Nile tilapia (Oreochromis niloticus) as biomarkers of exposure to polycyclic aromatic hydrocarbon (PAH) contaminations in tropical waters. Bile fluorescence profiles of the fish inhabiting two water bodies with different levels of PAH pollution (Weras Ganga and Bathalagoda reservoir) were investigated at regular intervals over two years (September 2007 to July 2009) using fixed wavelength fluorescence and synchronous fluorescence spectrometry. Despite temporal variability of the bile fluorescence patterns, the fluorescence signals corresponding to naphthalene-, phenanthrene-, pyrene- and benzo(a)pyrenetype metabolites were consistently higher in the fish from Weras Ganga compared to the fish from Bathalagoda reservoir and the laboratory maintained control fish indicating that the fish inhabiting Weras Ganga had been continuously exposed to higher levels of PAHs. Summated fluorescence for the four types of PAH metabolites and fluorescence signals corresponding to naphthalene- and pyrene- type metabolites in the fish from Weras Ganga were positively correlated $(\mathrm{P}<0.05)$ with the rainfall pattern indicating more PAH inputs associated with the rainfall. Despite slight temporal variations, no significant associations were found between the biliary fluorescence signals in the fish from Bathalagoda reservoir and the rainfall pattern. This field study supports the use of bile fluorescence patterns in feral Nile tilapia as a simple and rapid method for screening contamination and bioavailability of PAH in tropical freshwater bodies.
\end{abstract}

Keywords Tilapia, PAH, biomarker, bile fluorescence, fixed wavelength fluorescence, synchronous fluorescence spectrometry 


\section{Introduction}

Polycyclic aromatic hydrocarbons are ubiquitous organic pollutants containing two or more fused aromatic rings. PAHs are mainly derived from petrogenic (oil derived) and pyrogenic (combustion derived) sources. Sixteen PAHs have been categorized under the group "priority pollutants" which include naphthalene, phenanthrene, pyrene and benzo(a)pyrene. PAHs have been received increased attention in pollution studies as some PAHs are highly carcinogenic and mutagenic (Srogi, 2007). PAH contaminations in aquatic ecosystems pose a serious threat to aquatic resources including fish. In fish, PAHs can be readily biotransformed to hydrophilic metabolites which are accumulated in the bile before eliminated mainly via the alimentary tract. Because of extensive metabolism, detection of parent PAHs in fish tissues may underestimate the exposure level in vivo, and some PAHs present at low levels may fall under the level of analytical detection. Biliary PAH metabolite concentrations, on the other hand, are proven to be sensitive PAH exposure biomarkers and bile metabolites should therefore be the markers of choice for monitoring and environmental risk assessment studies concerning PAHcontaminant sites (van der Oost et al. 2003; Beyer, et al. 2010). Bioavailability of PAH in fish can be screened rapidly by simple methods such as fixed excitation/emission wavelength fluorescence and synchronous fluorescence spectrometry (Ariese, et.al. 1993; Aas, et.al. 2000; Beyer, et al. 2010).

Little information is available on PAH contaminations in tropical water bodies and effect of seasonal climatic factors. Occurrence of PAHs in Bolgoda Lake, an urban water body situated in the Western Province of Sri Lanka has been reported for the first time recently (Pathiratne et al. 2007). The extreme north end of the lake (Weras Ganga) is reported to contain relatively high levels of PAHs (Pathiratne et al. 2007; 2009). Further, PAH levels in water and sediments of Bathalagoda reservoir, (a non-urban waterbody in the North Western Province of the country) were found to be very low compared to the Bolgoda Lake (Pathiratne et al. 2009). These two water bodies are used by the local people for commercial fishing and domestic purposes. A recent laboratory exposure study with Nile tilapia (Oreochromis niloticus) has demonstrated the suitability of bile fluorescence patterns in this fish to investigate bioavailability of PAHs (Pathiratne et al. 2010). The present study is aimed at evaluating the potential use of bile fluorescence patterns of feral Nile tilapia (Oreochromis niloticus) as biomarkers of exposure to polycyclic aromatic hydrocarbon (PAH) contaminations in tropical waters especially in inland waters of Sri Lanka. In this study, biliary fluorescence patterns of Nile tilapia inhabiting Weras Ganga (a polluted water body) and Bathalagoda reservoir (a less polluted water body) were assessed as biomarkers of PAH exposure and the associations (if any) of temporal variations in the bioavailability of PAHs with the rainfall patterns in the areas were evaluated. 


\section{Feral fish}

\section{Materials and Methods}

The adult Nile tilapias $(17.3-25.5 \mathrm{~cm}$ in total length) inhabiting Weras Ganga and Bathalagoda reservoir were collected bimonthly for a period of two years from September 2007 to July 2009. Live fish irrespective of the gender were randomly selected from each water body in each sampling visit (8-30 fish) for analysis. Temperature and $\mathrm{pH}$ of the surface water of the study sites were monitored in situ during each sampling visit during the study period. Ranges of water temperature and $\mathrm{pH}$ of Weras Ganga were $29-31{ }^{\circ} \mathrm{C}$ and 6.2-8.0 respectively whereas the corresponding values in the water of Bathalagoda reservoir were $28-35{ }^{\circ} \mathrm{C}$ and $6.5-8.7$ respectively. Daily rainfall data in the study areas were obtained from the Meteorological Department, Colombo, Sri Lanka.

\section{Control fish}

Nile tilapias that were used as controls (18 $-23 \mathrm{~cm}$ in total length) were obtained from Udawalawe freshwater fish breeding station, National Aquaculture Development Authority, Sri Lanka and were maintained in the laboratory in fiberglass tanks filled with continuously aerated aged tap water for several weeks prior to the analysis. The fish were daily fed with commercial fish food pellets (Ceylon Grain Elevators Pvt Ltd., Sri Lanka) at $2 \%$ of the body weight. Water temperature and $\mathrm{pH}$ the fish rearing tanks were 27-31 ${ }^{\circ} \mathrm{C}$ and 6.9-7.5 respectively. The control fish were taken at appropriate time intervals for analysis of bile.

\section{Analysis of bile}

Fish were anesthetized using benzocaine. Bile was taken to a syringe by puncturing the gall bladder and frozen with liquid nitrogen and stored at $80^{\circ} \mathrm{C}$ in an ultra-low temperature freezer until further processing. PAH metabolites in fish bile were determined by fixed fluorescence and synchronous fluorescence scanning techniques using computer controlled Varian Cary Eclipse fluorescence spectrophotometer. Two $\mu \mathrm{L}$ of bile diluted in $4 \mathrm{~mL}$ of $48 \%$ ethanol were used to decrease self-absorption and quenching of the fluorescence signal. Fixed fluorescence at the excitation/emission wavelength pairs 290/335 nm, 341/383 nm and 380/430 nm were determined for naphthalene type-, pyrene type- and benzo(a)pyrene metabolites respectively (Aas, et al. 2000). For detection of phenanthrene typemetabolites, fixed fluorescence at the wavelength pair 260/380 nm was used (Krahn et al. 1993). The excitation/emission slit widths were adjusted to 2.5 $\mathrm{nm}$. The fluorescence values were obtained as arbitrary fluorescence units after deducting the signal level of the solvent (Aas, et al. 2000). Total fluorescent metabolites were calculated as the summated specific fluorescence for the four types of metabolites measured (Ferreira et al. 2010). For synchronous fluorescence scanning, fluorescence recordings of bile samples were taken in the range of 230-500 $\mathrm{nm}$ wavelengths with a difference between excitation and emission wavelengths $(\Delta \lambda)$ of $42 \mathrm{~nm}$ 
maintaining slit widths at $2.5 / 5 \mathrm{~nm}$ for detection of naphthalene type-, pyrene type- and benzo(a)pyrene metabolites (Aas, et al. 2000). Bile intensity was measured at $660 \mathrm{~nm}$ in all samples to estimate the biliverdin content (Larson et al. 1947).

\section{Data analysis}

Temporal and site specific variations in the fluorescence patterns of fish were analyzed separately by one way analysis of variance (ANOVA). Where differences were significant $(\mathrm{P}<0.05)$ multiple comparisons were carried out by Tukey's test as appropriate. Associations between the rainfall pattern and bile fluorescence corresponding to PAH metabolites were tested using Pearson Correlation test $(\mathrm{P}<0.05)$. Cumulative rainfall data in the study sites corresponding to $7,14,21$ and 28 days prior to the sampling dates of each sampling visit were used for the data analysis. For all the statistical analysis the data were transformed to $\log (\mathrm{X}+1)(\mathrm{Zar}, 1999)$.

\section{Results}

In the synchronous fluorescence scan of bile (Fig. 1), Nile tilapia collected from the Weras Ganga showed prominent peaks at 284/326 nm and 340/382 $\mathrm{nm}$ excitation/emission wavelengths corresponding to naphthalene type- and pyrene type- metabolites respectively. In addition a minor peak was detected at $380 / 422 \mathrm{~nm}$ which is related to benzo[a]pyrene type- metabolites. The bile of control fish did not show any prominent peaks at the points corresponding to the respective PAH metabolites. The fluorescence scans of the bile of fish collected from Bathalagoda reservoir generally followed the same pattern as the control fish. However a slight peak corresponding to naphthalene typemetabolites was evident in some occasions.

Biliverdin contents in the bile of Nile tilapia collected from Weras Ganga and Bathalagoda reservoir were 0.34-2.7 pmols and 0.39-3.2 pmols in $2 \mu \mathrm{l}$ of bile respectively. Biliverdin content in fish bile varied considerably among the fish sampled from the same site in each sampling occasion. Hence fixed fluorescence signals were not normalized to biliverdin content. Biliary fixed fluorescence signals corresponding to naphthalene type- (2 aromatic rings), phenanthrene type- (3 aromatic rings), pyrene type- (4 aromatic rings) and benzo(a)pyrene type- (5 aromatic rings) metabolites in Nile tilapia inhabiting Weras Ganga varied considerably during the study period (Fig. 2) where as minor fluctuations of respective fluorescence signals were obtained for the fish collected from Bathalagoda reservoir. In general, much lower fluorescence patterns corresponding to phenanthrene type-, pyrene type- and benzo(a)pyrene type- metabolites in the fish from Weras Ganga were obtained in January 2008 and 2009 in comparison to the rest of the sampling periods. Despite significant temporal variations of the fluorescence pattern $(\mathrm{P}$ $<0.05$ ), fluorescence signals corresponding to the four types of PAH metabolites were consistently higher $(\mathrm{P}<0.05)$ in the fish from Weras Ganga than those of the fish from Bathalagoda reservoir and control fish. The 
fluorescence signals corresponds to naphthalene type- metabolites were much greater in the fish from Weras Ganga especially in March and December 2008 whereas the fluorescence corresponds to phenanthrene type- metabolites were significantly higher during the study period except in January and December 2008, January and May 2009. Fluorescence signals relevant to pyrene type metabolites were much higher in the fish from the Weras Ganga site during the whole study period except in January 2008, January and March 2009. A notable high fluorescence with respect to benzo(a)pyrene metabolites in the fish from Weras Ganga site was obtained in December 2008.

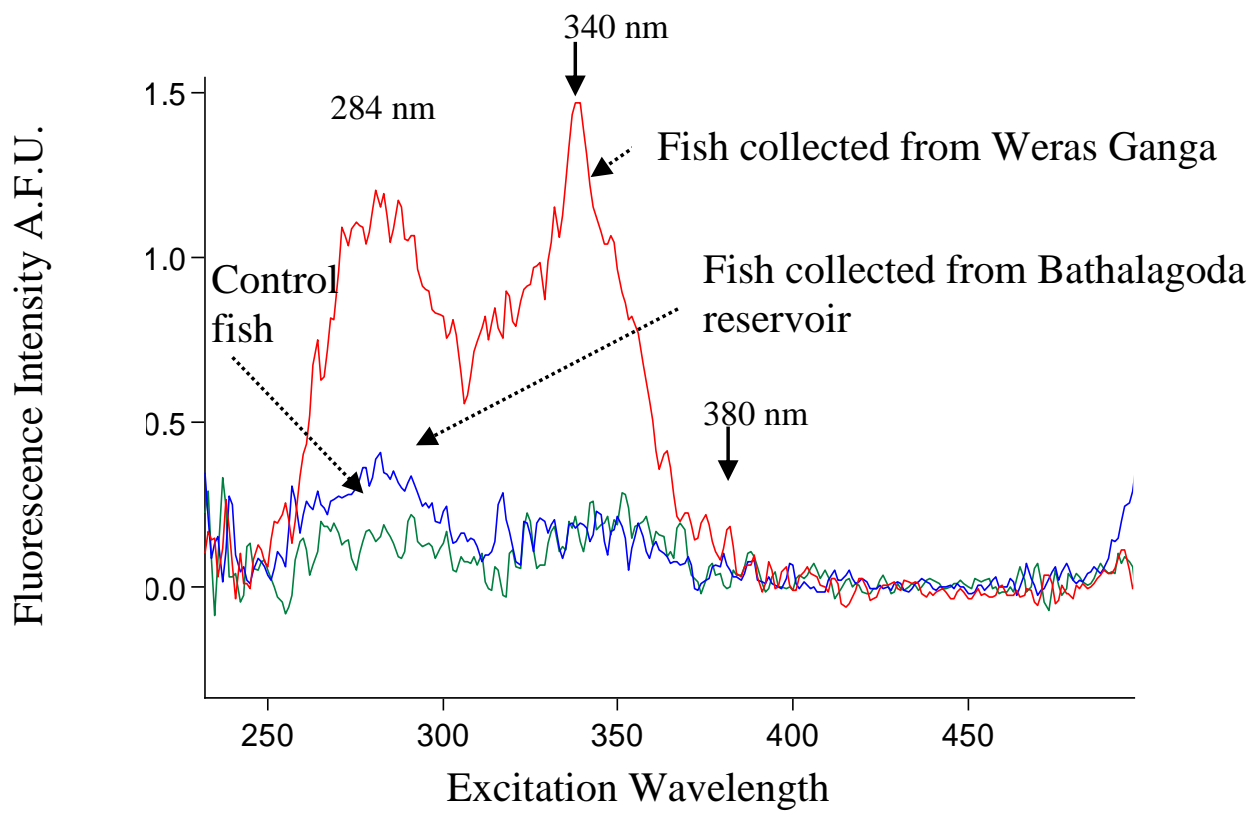

Figure 1. Synchronous fluorescence spectra of bile of Nile tilapia inhabiting Weras Ganga and Bathalagoda Reservoir. Fluorescence pattern of the control fish is shown for comparison. A.F.U - Arbitrary Fluorescence Units 
(a) Napthalene type metabolites

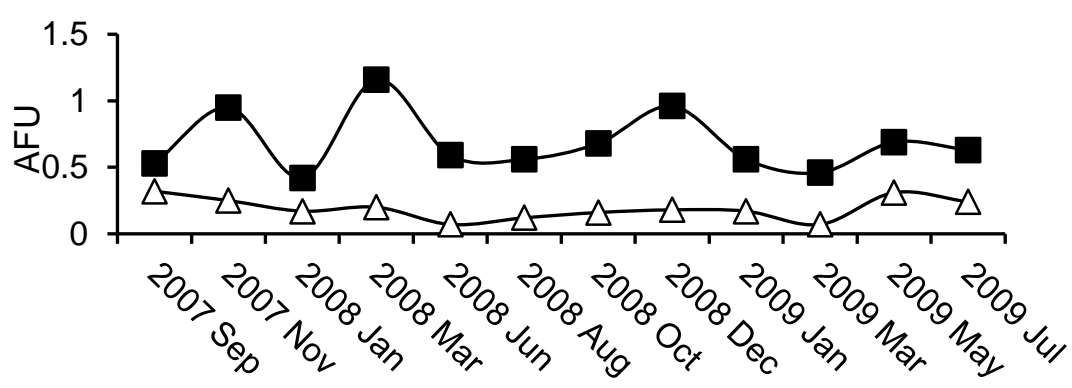

(b) Phenanthrene type metabolites
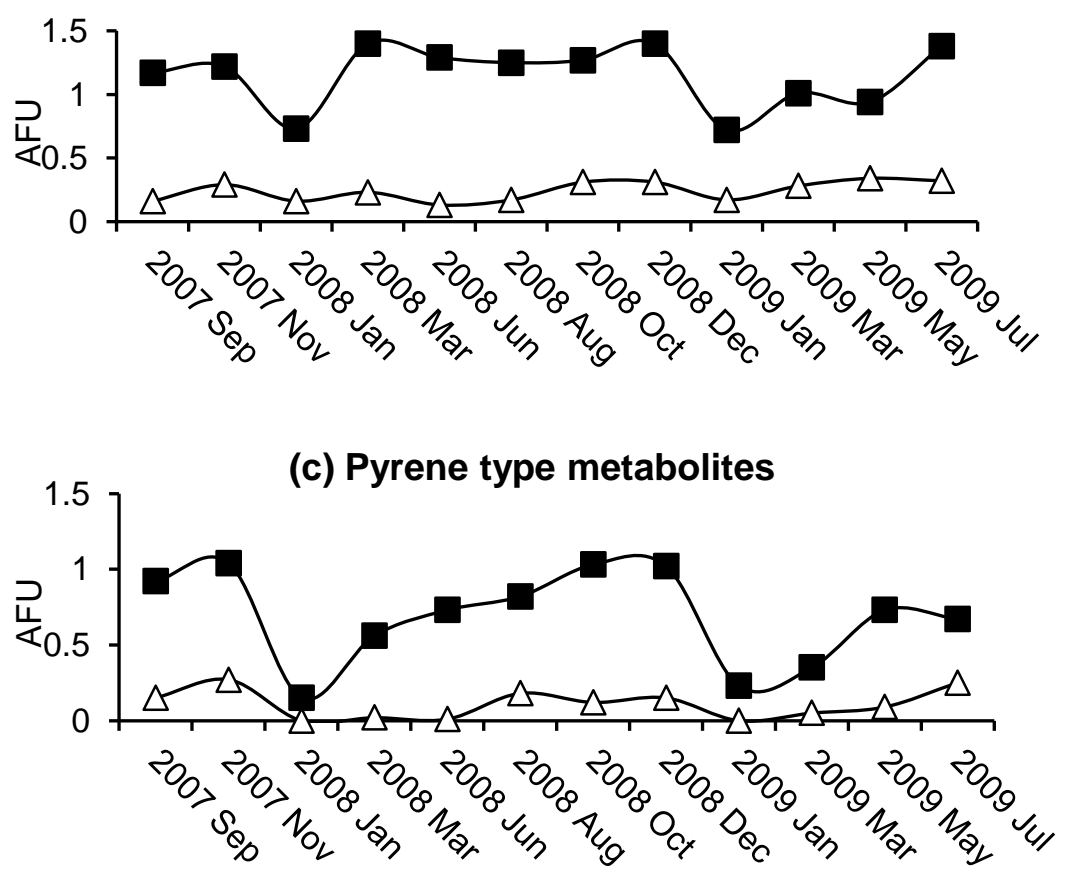


\section{(d) Benzo(a)pyrene type metabolites}

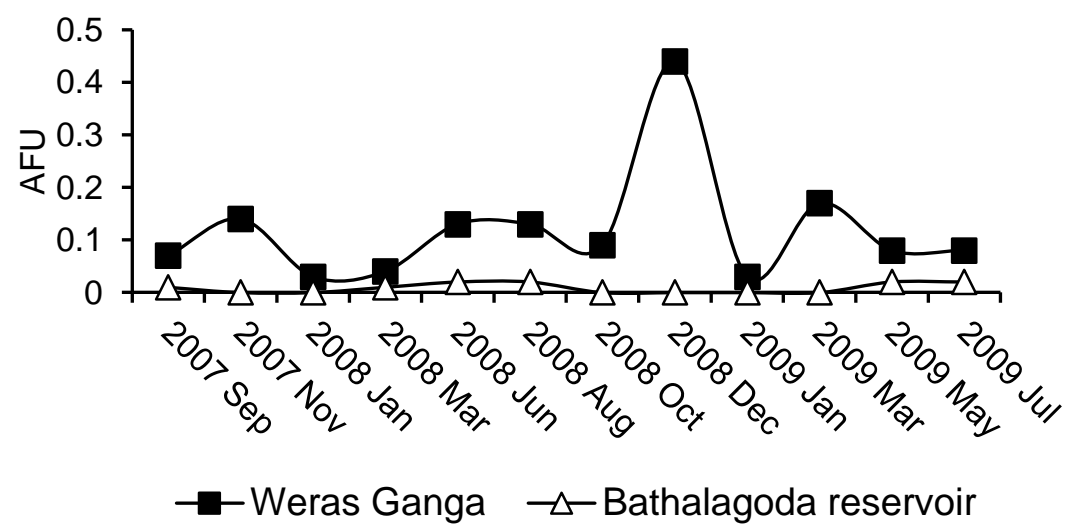

Figure 2. Temporal variations in the fixed wavelength fluorescence patterns of bile of Nile tilapia collected from Weras Ganga and Bathalagoda reservoir during the study period. Data are presented as mean of 8-30 fish per sampling event. A.F.U - Arbitrary fluorescent units

Association of temporal variations in the biliary fluorescence corresponding to the summated fixed wavelength fluorescence corresponding to the four types of PAH metabolites of the fish with the cumulative rainfall 28 days prior to each sampling date are presented in the Fig. 3. Cumulative rainfall (28 days prior to each sampling date) was greater than $200 \mathrm{~mm}$ in Weras Ganga area during March, October and December in 2008, and May in 2009. Significant positive correlations $(P<0.05)$ were obtained between the rainfall in the area and biliary fluorescence signals corresponding to the sum of the specific fluorescence for the four types of metabolites measured in the fish (Table 1). In addition bile fluorescence signals of the fish corresponding to naphthalene type- and pyrene type- metabolites were positively correlated $(\mathrm{P}<0.05)$ with the rainfall pattern. Positive correlation $(\mathrm{P}<0.05)$ patterns were obtained with these PAH metabolites and cumulative rainfall prior to 14, 21 and 28 days of the sampling events (Table 1). High cumulative rainfall (> $200 \mathrm{~mm}$ ) was also experienced in Bathalagoda reservoir area during the periods, September 2007, March, October and December in 2008 (Figure 3). However no significant correlations $(\mathrm{P}>0.05)$ were found between the rainfall pattern and the biliary fluorescence signals in the fish from Bathalagoda reservoir (Table 1). 


\section{Weras Ganga}

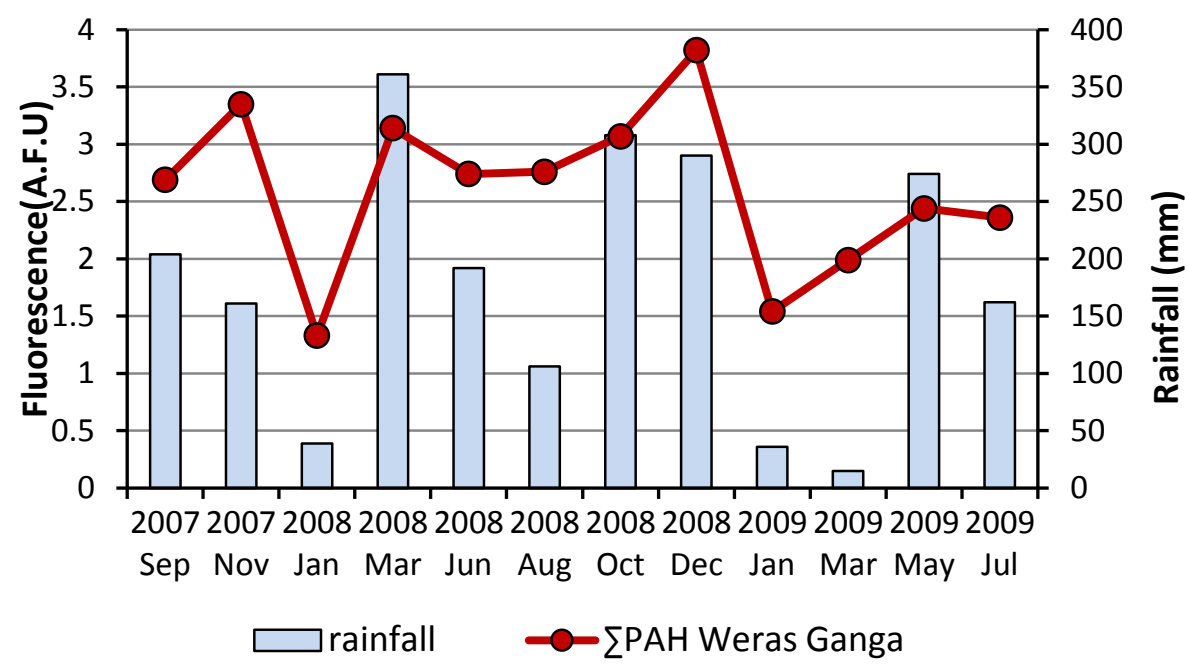

\section{Bathalagoda Reservoir}

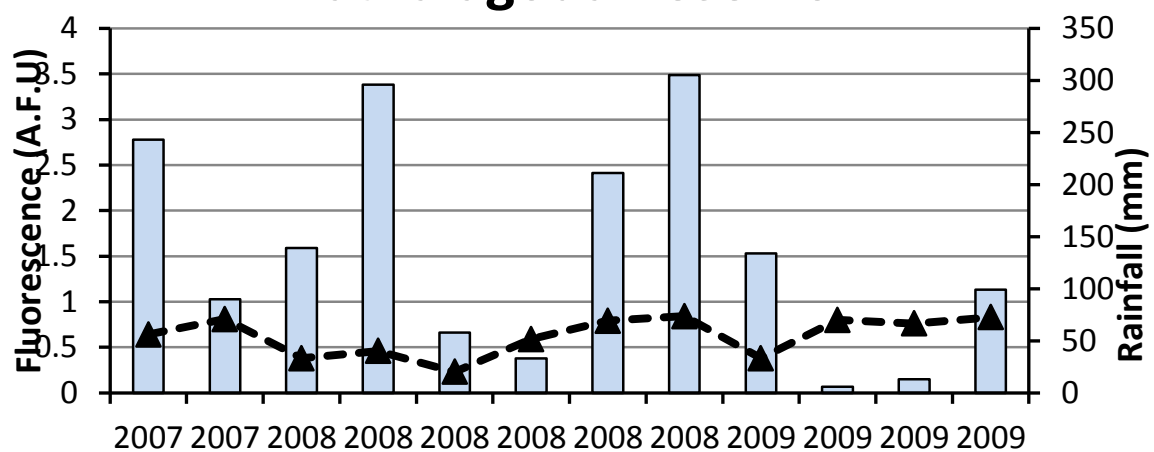

Sep Nov Jan Mar Jun Aug Oct Dec Jan Mar May Jul

$\square \quad- \pm$ - $\square$ PAH Bathalagoda

Figure 3. Summated biliary fixed wavelength fluorescence (for $\sum \mathrm{PAH}$ ) of Nile tilapia collected from Weras Ganga and Bathalagoda reservoir and rainfall pattern in the area during the study period. Fluorescence data are presented as mean of 8-30 fish per study site in each sampling event. A.F.U Arbitrary fluorescent units 
Table 1. Correlations between the fixed wavelength fluorescence related to PAH metabolites in the bile of Nile tilapia collected from Weras Ganga and Bathalagoda reservoir and the cumulative rainfall to the area prior to 7, 14, 21 and 28 days of fish sampling.

\begin{tabular}{|l|c|c|c|l|}
\hline \multirow{2}{*}{ Bile fluorescence } & \multicolumn{4}{|c|}{$\begin{array}{c}\text { Pearson correlation coefficient between } \\
\text { fluorescence and rainfall }\end{array}$} \\
\cline { 2 - 5 } & $\begin{array}{c}\text { Rainfall } \\
\text { prior to } \\
7 \text { days }\end{array}$ & $\begin{array}{c}\text { Rainfall } \\
\text { prior to } \\
14 \text { days }\end{array}$ & $\begin{array}{c}\text { Rainfall } \\
\text { prior to } \\
21 \text { days }\end{array}$ & $\begin{array}{c}\text { Rainfall } \\
\text { prior to } \\
28 \text { days }\end{array}$ \\
\hline Weras Ganga & 0.203 & $0.633^{*}$ & $0.601^{*}$ & $0.607^{*}$ \\
Naphthalene type & 0.164 & 0.434 & 0.501 & 0.557 \\
Phenanthrene type & 0.561 & $0.592^{*}$ & $0.588^{*}$ & $0.675^{*}$ \\
Pyrene type & 0.021 & 0.049 & 0.015 & 0.028 \\
Benzo(a)pyrene type & 0.357 & $0.588^{*}$ & $0.600^{*}$ & $0.663^{*}$ \\
summated fluorescence & & & & \\
\hline Bathalagoda reservoir & 0.427 & 0.309 & 0.369 & 0.319 \\
Naphthalene type & -0.093 & -0.171 & -0.160 & -0.156 \\
Phenanthrene type & 0.157 & -0.347 & -0.311 & -0.326 \\
Pyrene type & 0.126 & 0.126 & -0.146 & -0.137 \\
summated fluorescence & & & & \\
\hline
\end{tabular}

*Significant at $\mathrm{P}<0.05$

\section{Discussion}

Based on the controlled laboratory exposure studies, the optimal wavelength pairs (excitation/emission) for synchronous fluorescence scanning measurements $(\Delta \lambda=42 \mathrm{~nm})$ of bile metabolites of naphthalene and pyrene for Nile tilapia have been identified as 284/326 nm, and 340/382 nm respectively (Pathiratne, et al. 2010). In the present study, Nile tilapia collected from the Weras Ganga showed prominent peaks at these excitation/emission wavelengths $(\Delta \lambda=42 \mathrm{~nm})$ corresponding to naphthalene type- and pyrene type metabolites. In addition a minor peak was detected at $380 / 422 \mathrm{~nm}$ which is related to benzo[a]pyrene type- metabolites (Aas et al. 2000). The main peaks observed in the fluorescence scans of the bile taken from feral Nile tilapia may be mainly due to the glucuronide conjugates as previous studies on some other fish species indicate that main PAH metabolites in the bile are glucuronides (Varanasi et al. 1981; Leonard \& Hellou, 2001).

The occurrence of PAHs in the environment is largely as a result of anthropogenic emissions such as fossil fuel burning, motor vehicle, waste incineration and industrial effluents etc. (Srogi, 2007). PAH contamination originating from petrogenic sources shows a dominance of two and three ring compounds over four and five ring compounds, while pyrogenic PAH is dominated by four and five ring compounds (Neff, 1979). A previous chemical study on occurrence and distribution of PAH pollution in Bolgoda 
Lake reported higher occurrence of 4-5 ring PAHs such as benzo(k)fluoranthene, pyrene, chrysene, 1-nitropyrene, benzo(a)pyrene, dibenz(a,h)anthracene in sediments sampled during 2003-2004 from the lake especially at Weras Ganga site in comparison to the 2-3 ring PAHs viz. naphthalene, acenaphthene, phenanthrene, anthracene, and fluoranthene (Pathiratne et al. 2007). A more recent study also provides evidence for the occurrence of pyrogenic and petrogenic PAHs in Bolgoda North Lake (Pathiratne et al. 2009). The present study examined the temporal variations in the bioavailability of PAHs in extreme north side of this urban lake (Weras Ganga) using fixed fluorescence and synchronous fluorescence techniques. Although these fluorescence techniques are not for quantification purposes of specific PAH compounds, they are simple and sensitive method for screening specific PAH contamination in fish to discern between sites of varying PAH exposure (van der Oost et al. 2003; Beyer 2010). Based on the biliary fixed fluorescence and synchronous fluorescence patterns of feral Nile tilapia, the present study revealed that the fish residing in Weras Ganga had been consistently exposed to higher levels of PAHs from pyrogenic sources as well as petrogenic sources compared to the fish from non-urban reservoir (Bathalagoda reservoir) and the laboratory maintained control fish. PAHs enter surface waters mainly via atmospheric fall out, urban run-off, municipal effluents, industrial effluents and oil spillage and leakage (Srogi, 2007). Land based pollution sources of Weras Ganga especially domestic waste, fuel stations and industrial effluents may have contributed significant amounts of PAHs to these two sites. Particularly in urban areas, runoff from impervious surfaces, such as roads and parking lots, contributes significant quantities of pollutants to surrounding surface water bodies (Krein \& Schorer, 2000; Smith et al. 2000; Mahler et al. 2005). Main roads located near the vicinity of Weras Ganga and vehicle emissions may have been additional sources of PAHs in this location.

In Sri Lanka, two rainy seasons have been identified viz. south west monsoon (May to September) and north east monsoon (December to February). In addition, heavy rains can occur during inter-monsoon periods (March -April; October-November) depending on the changes in weather patterns. In the present study, the Weras Ganga area experienced heavy rain during south west monsoon periods (September 2007 and May 2009), north east monsoon period (December 2008) and inter-monsoon periods (March and October 2008). In general the rainfall in the non-urban reservoir area followed the same pattern except in May 2009 during which the rainfall was very low. Nonetheless, significant positive correlations were obtained between the rainfall in the area and biliary fluorescence signals corresponding to the summated specific fixed wavelength fluorescence for the four types of metabolites measured in the fish from the Weras Ganga. In addition bile fluorescence signals of the fish from Weras Ganga corresponding to naphthalene type- and pyrene type- metabolites were positively correlated with the rainfall pattern. Significant positive correlation patterns were obtained with these PAH metabolites and cumulative rainfall prior to 14, 21 
and 28 days of the sampling events. The results suggest that inputs of pyrogenic and petrogenic PAHs to the urban water body were increased in association with the heavy rainfall to the area probably via urban runoff. Urban run-off contains PAHs deposited on surfaces, as well as mobile related PAHs from gasoline and oil drips or spills, exhaust products, tyre particles, and bitumen from road surfaces (Srogi 2007). Even though temporal fluctuations in PAH bioavailability in Weras Ganga can be attributed to the rainfall pattern, other variables such as direct local inputs from other pollution sources cannot be overlooked.

In conclusion, long term temporal variations in biliary fluorescence patterns in Nile tilapia inhabiting the two tropical water bodies by fixed wavelength fluorescence and synchronous fluorescence spectrometry showed that the fluorescence signals corresponding to naphthalene type-, phenanthrene type-, pyrene type- and benzo(a)pyrene type- metabolites were consistently higher in the fish from the urban water body (Weras Ganga) compared to the non-urban reservoir (Bathalagoda reservoir) reflecting continuous occurrence of petrogenic and pyrogenic PAHs in the urban water body. Significant positive correlations between rainfall in the area and biliary fluorescence signals measured in the fish from the urban water body indicate increasing inputs of petrogenic and pyrogenic PAHs associated with the heavy rainfall probably via urban runoff in addition to the direct inputs from other local pollution sources. Upon entering the water, these contaminants can remain in the water body for long periods especially by adsorbing to sediments and biota posing a threat to aquatic life and human health. This field study supports the use of bile fluorescence patterns in feral Nile tilapia as a simple and rapid method for screening temporal trends in PAH contaminations in tropical freshwater bodies.

\section{Acknowledgements}

This study was financially supported by the National Research Council (Grant number 05-24) and the National Science Foundation of Sri Lanka (Grant number RG/2006/EB/07).

\section{References}

Aas, E., J. Beyer, \& A. Goksoy 2000.

Fixed wavelength fluorescence (FF) of bile as a monitoring tool for polyaromatic hydrocarbon exposure in fish: an evaluation of compound specificity, inner filter effect and signal interpretation. Biomarkers 5: 923.

Ariese, F., S.J. Kok, M. Verkaik, C. Gooijer, N.H. Velthorst \& J.W. Hofstraaat 1993.

Synchronous fluorescence spectrometry of fish bile: A rapid screening method for the biomonitoring of PAH exposure. Aquatic Toxicology 26: 273-286. 
Beyer, J., G. Jonsson, C. Porte, M.M. Krahn, \& F. Ariese 2010.

Analytical methods for determining metabolites of polycyclic aromatic hydrocarbon (PAH) pollutants in fish bile: A review. Environmental Toxicology and Pharmacology 30:224-244.

Ferreira, M., P. Moradas-Ferreira. \& M.A. Reis-Henriques, 2006.

The effect of long term depuration on phase I and phase II biotransformation in mullets (Mugil cephalus) chronically exposed to pollutants in River Douro Estuary, Portugal. Marine Environmental Research 61: 326-338.

Krahn, M.M., G.M. Ylitalo, J. Buzitis, S.L Chan, U. Varanasi, T.L Wade, T.J. Jackson, J.M. Brooks, D.A Wolfe. \& C.A. Manen 1993.

Comparison of high performance liquid chromatography/ fluorescence scanning and gas chromatography/mass spectrometry analysis for aromatic compounds in sediment samples after Exxon valdez oil spill. Environment Science and Technology 27: 699-708.

Krein, A. \& M. Schorer 2000.

Road runoff pollution by polycyclic aromatic hydrocarbons and its contribution to river sediment. Water Research 34: 4110-4115.

Larson, E. ., G.T. Evans \& C.J. Watson 1947.

A study of the serum biliverdin concentration in various types of Jaundice. Journal of Laboratory and Clinical Medicine 32: 481-488.

Leonard, J.D. \& J. Hellou, 2001.

Separation and characterization of gall bladder bile metabolites from speckled trout, Salvelinus fontinalis exposed to individual polycyclic aromatic hydrocarbons. Environmental Toxicology and Chemistry 20: 618-623.

Mahler, B.J, P. C. van Metre, T. Bashara, J.T. Wilson \& D.A. Johns 2005. Parking lot sealcoats: an unrecognized source of urban polycyclic aromatic hydrocarbons. Environment Science and Technology 39: 5560-5566.

Neff, J.M. 1979.

Polycyclic Aromatic Hydrocarbons in the Aquatic Environment. Sources, Fates and Biological Effects. Barking, Essex, England:Applied Sciences.

Pathiratne, K.A.S., O.C.P. De Silva, D. Hehemann, I. Atkinson \& R. Wei. 2007.

Occurrence and distribution of polycyclic aromatic hydrocarbons (PAHs) in Bolgoda and Beira Lakes, Sri Lanka. Bulletin of Environmental Contamination and Toxicology 79: 135-140.

Pathiratne, A., L.W.H.U. Chandrasekera, \& K.A.S. Pathiratne 2009.

Use of biomarkers in Nile tilapia (Oreochromis niloticus) to assess the impacts of pollution in Bolgoda Lake, an urban water body in Sri Lanka. Environmental Monitoring and Assessment 156: 361-375. 
Smith, J. A., M. Sievers, S. Huang \& S.L. Yu, 2000.

Occurrence and phase distribution of polycyclic aromatic hydrocarbons in urban storm-water runoff. Water Science and Technology 42: 383388.

Srogi, K. 2007.

Monitoring of environmental exposure to polycyclic aromatic hydrocarbons: a review. Environmental Chemistry Letters 5: 169-195.

Pathiratne, A., C.K. Hemachandra \& K.A.S. Pathiratne 2010.

Assessment of bile fluorescence patterns in a tropical fish, Nile tilapia (Oreochromis niloticus) exposed to naphthalene, phenanthrene, pyrene and chrysene using fixed wavelength fluorescence and synchronous fluorescence spectrometry. Bulletin of Environmental Contamination and Toxicology 84: 554-558.

van der Oost, R., J. Beyer, \& N.P.E. Vermeulan 2003.

Fish bioaccumulation and biomarkers in environmental risk assessment: a review. Environmental Toxicology and Pharmacology 13: 57-149.

Varanasi, U., D.J. Gmur, \& L.R. William 1981.

Effect of environmental temperature on naphthalene metabolism by juvenile starry flounder (Platichthys stellatus). Archives of Environmental Contamination and Toxicology 10: 203-214.

Zar, J.H. 1999.

Biostatistical Analysis. Prentice Hall, Upper Saddle River, New Jersey. 